\title{
V. Ameigen.
}

programm für die XXIII. Derfammlung deutfcher forjtmänner in Würzburg vom 26,-30. 2fuguft 1895. 1)

I. Beiteinteilumg.

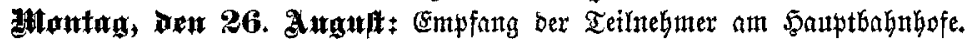

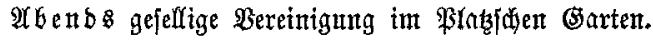

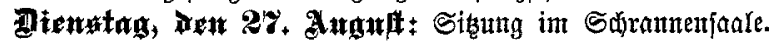

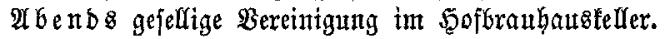

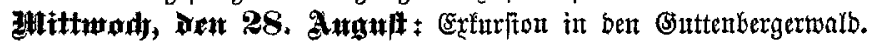

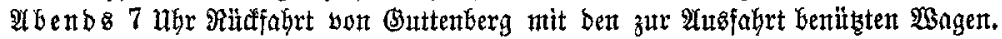

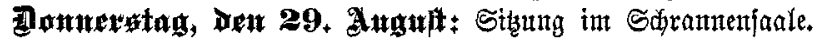

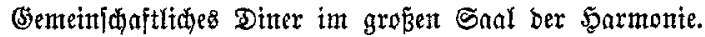

Gartenunterfaltung im 5uttem[chen (5arten.

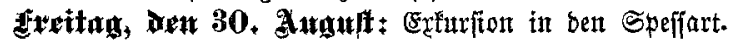

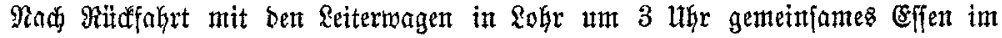

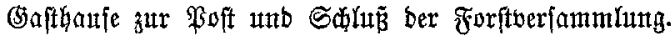

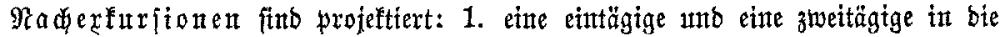

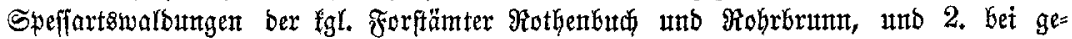

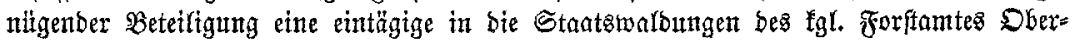

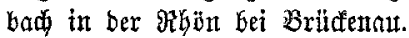

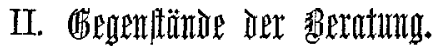

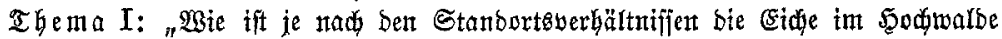
zut exziefyen unb bis zu ihrer \$̧aubarfeit zat Gehandern?"

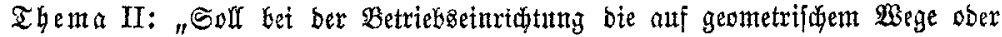

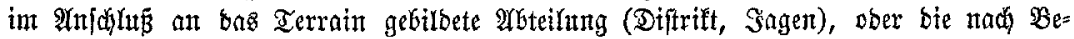

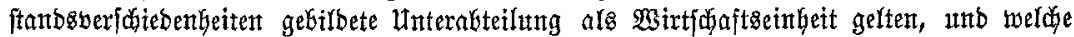

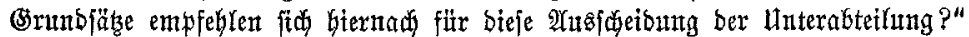

Thenta III: Mitteilungent ïber $\mathfrak{b e r i t a j e , ~ B e n b a d t u n g e n , ~ E r f a b r u n g e n ~ u n b ~ b e s ~}$

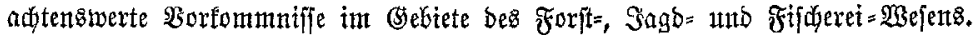

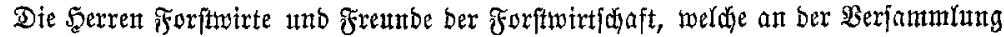

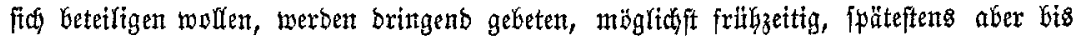

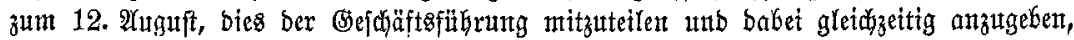
ob fie an ben Exyfurftonen itt Sent (Bnttenbergerwalb unt' nad Rohr, fowote an bem Ditter

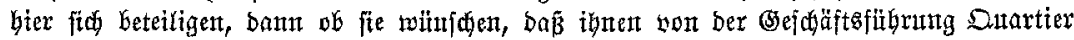

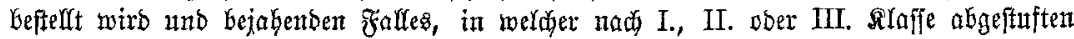

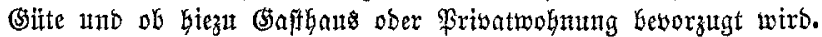

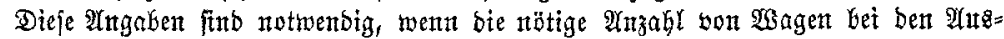
flitgen, Duartier unb gute Bersflegutrtg yöllig fidfer geftellt werben follen.

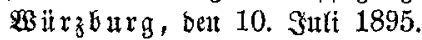

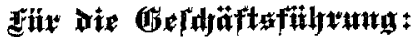 \\ Rle efpies, figl. Oberforftrat.}

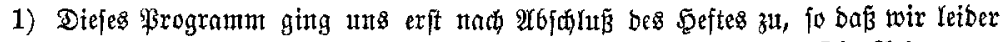

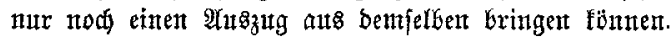

Die Reb. 